\title{
Design to Data for mutants of $\beta$-glucosidase B from Paenibacillus polymyxa: I45K, A357S, I20A, I20V, and I20E
}

\author{
Jennie A. Luong ${ }^{1}$, Ashley Vater ${ }^{1}$, Justin B. Siegel ${ }^{123}$ \\ ${ }^{1}$ Genome Center, University of California, Davis 95616, California, United States \\ ${ }^{2}$ Department of Biochemistry \& Molecular Medicine, University of California, Davis 95616, California, United States \\ ${ }^{3}$ Department of Chemistry, University of California, Davis 95616, California, United States
}

*Corresponding author; email: jbsiegel@ucdavis.edu

\begin{abstract}
The relatively small size and scope of most current datasets of biophysical mutation effects in enzymes limit the ability to develop data-driven algorithms enabling accurate generative modeling tools for designing novel enzyme function. Here, the Michaelis-Menten constants $\left(k_{\mathrm{cat}}, \mathrm{K}_{\mathrm{M}}\right.$, and $\left.k_{\mathrm{cat}} / \mathrm{K}_{\mathrm{M}}\right)$ and thermal stability $\left(\mathrm{T}_{\mathrm{M}}\right)$ of five new mutations of $\beta$-glucosidase B from Paenibacillus polymyxa (BglB) are characterized. Foldit software was used to create molecular models of the mutants, for which synthetic genes were constructed and the corresponding proteins produced and purified from E. coli. It was found that mutations that disrupted pre-existing hydrogen bonds near the active site had reduced expression in contrast to mutations at the same site that did not affect native hydrogen bonding. This is consistent with previous results showing the relationship between hydrogen bonding and enzyme functionality. These mutants contribute to a growing data set of $>100$ mutants that have been characterized for expression, kinetic, and thermal properties
\end{abstract}

\section{INTRODUCTION}

Enzymes are the primary means of catalyzing chemical reactions in biological systems and are becoming more important in the development of therapeutics. ${ }^{1,2}$ Protein engineering can be used to create stable, efficient enzymes for reactions that are not catalyzed by natural biocatalysts. ${ }^{1}$ Two factors that are often key considerations when creating biocatalyst are (1) the denaturation temperature and (2) the efficiency of reaction catalyzation. ${ }^{3}$ While large standardized datasets for protein structures exist, ${ }^{4}$ the field lacks large, quantitative standardized datasets of enzyme functional properties. While powerful and accurate tools for modeling protein structure are rapidly evolving, the lack of data has limited the ability to develop robust predictive algorithms for a proteins functional properties. ${ }^{5,6}$ While structure is critical for function large and consistently generated data sets are needed to better capture the subtleties from which a proteins structure imparts its function. ${ }^{7}$

To address this gap there are growing efforts to create large data sets of large data sets directly connecting protein sequencestructure-function relationships. Of particular relevance to this study are efforts to quantitatively characterize a growing library of mutants for the Paenibacillus polymyxa beta-glyhcosidase $B$ (BglB), for which >100 mutants have now been produced and systematically characterized for expression, kinetic, and thermal properties. ${ }^{8,9}$ In this study, a total of five single-point

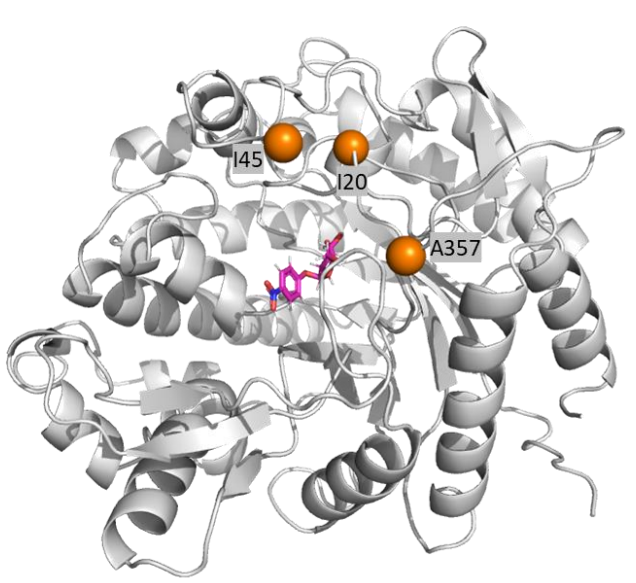

Figure 1. Location of mutant sites on BglB from Paenibacillus polymyxa. Pymol $^{11}$ rendering of $\mathrm{BglB}$. The three mutational sites used in the study are indicated in orange spheres. The substrate is indicated in pink and the main enzyme is shown in grey.

BglB mutants were modeled, synthetic genes constructed, and corresponding proteins biophysically characterized. Mutants were designed using Foldit ${ }^{10}$. The thermal stability of the mutant was predicted by the total system energy score (TSE) ${ }^{6}$ 
bioRxiv preprint doi: https://doi.org/10.1101/2020.10.07.330233; this version posted October 7, 2020. The copyright holder for this preprint (which was not certified by peer review) is the author/funder, who has granted bioRxiv a license to display the preprint in perpetuity. It is made available under aCC-BY-NC-ND 4.0 International license.

and catalytic efficiency was predicted by the ligand energy. Within this set, two of the mutant's models showed a change in intermolecular forces and three preserved those of the native structure. The mutants $\mathrm{A} 357 \mathrm{~S}$ and $\mathrm{I} 20 \mathrm{E}$ were predicted to have a decreased overall catalytic efficiency $\left(k_{\text {cat }} / \mathrm{K}_{\mathrm{M}}\right)$ and mutants I20A, I $20 \mathrm{~V}$, and $\mathrm{I} 45 \mathrm{~K}$ were predicted to have no change in overall catalytic efficiency. Mutant I45K was hypothesized to have an increase in overall thermal stability and all other mutants were predicted to have a decreased thermal stability. Based on the TSE and ligand energy alone, only three of the five mutants' functional performance aligned with what was initially hypothesized. In this small sample set, there appears to be a trend between the variants' expression, thermal stability, and catalytic efficiency in relationship to changes in the modeled intermolecular interactions-where small, noninterruptive changes had little effect on functionalities and disruptive changes considerably diminished functionality.

\section{METHODS}

\section{Mutation Design}

Foldit was used with a previously described $\operatorname{method}^{8}$ to model the five-point mutations. The mutations were scored by the Rosetta energy function and both a TSE and ligand energy were given. ${ }^{6}$ Mutants were chosen, in part, to have similar TSE values as the wild type, within 5 points of the wild type energy score.

\section{Generating Synthetic Genes of Mutants}

Plasmids containing a synthetic gene encoding the mutant proteins were generated with standard Kunkel Mutagenesis procedure. ${ }^{12}$ Plasmids were electroporated into Dh5alpha competent E.coli cells and plated onto Luria-Bertani agar plates with $50 \mu \mathrm{g} / \mathrm{mL}$ kanamycin. Individual colonies were sequenced via sanger sequencing after overnight growth to identify mutants.

\section{Protein Purification and Production}

The sequence verified BglB mutants were grown, and expressed using previously described methods. ${ }^{9}$ After inducing protein expression with IPTG, the cells were lysed and immobilized metal ion affinity chromatography was used to purify proteins. Protein yield was determined by A280 using a BioTek ${ }^{\circledR}$ Epoch spectrophotometer and protein purity was assessed by SDS-PAGE gel.

\section{Michaelis Menten Kinetics and Thermal Stability}

Kinetic characterization was done using a previously described method. ${ }^{8}$ Activity of the enzyme was measured using the production rate of 4-nitrophenol from p-nitrophenyl-betaD-glucoside. The measurements were determined and recorded through A420 spectrophotometry assay for 1 hour. $k_{\text {cat }}$ and $K_{M}$ were determined by fitting the data to the Michaelis-Menten kinetics model. ${ }^{13}$ The thermal stability $\left(\mathrm{T}_{\mathrm{M}}\right)$ for the variants were determined using Protein Thermal Shift ${ }^{\mathrm{TM}}$ kit made by Applied BioSystem ${ }^{\circledR}$ from ThermoFisher. Following the standard protocol by the manufacturer, purified proteins were diluted from 0.1 to $0.5 \mathrm{mg} / \mathrm{mL}$ and fluorescence reading was monitored using QuantaStudio ${ }^{\mathrm{TM}} 3$ System from $20^{\circ} \mathrm{C}$ to 90 ${ }^{\circ} \mathrm{C}$. The $\mathrm{T}_{\mathrm{M}}$ values were then determined using the two-state Boltzmann model from the Protein Thermal Shift ${ }^{\mathrm{TM}}$ Software 1.3 by Applied BioSystem ${ }^{\circledR}$ from Thermo Fisher.

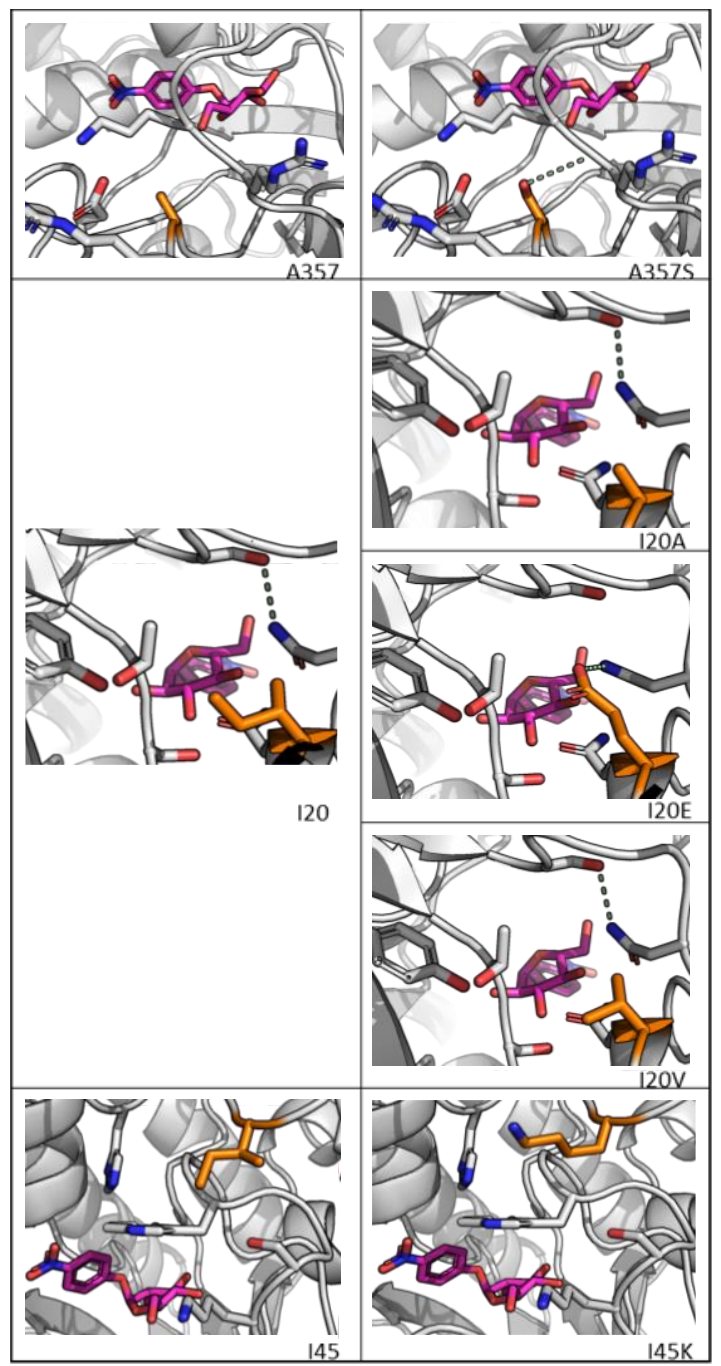

Figure 2. Structural Representation of BglB Mutants. Mutations are illustrated using $\mathrm{PyMOL}^{6}$ generated images showing the positions of the mutated amino acid (orange), the ligand (pink), and hydrogen bonds (green).

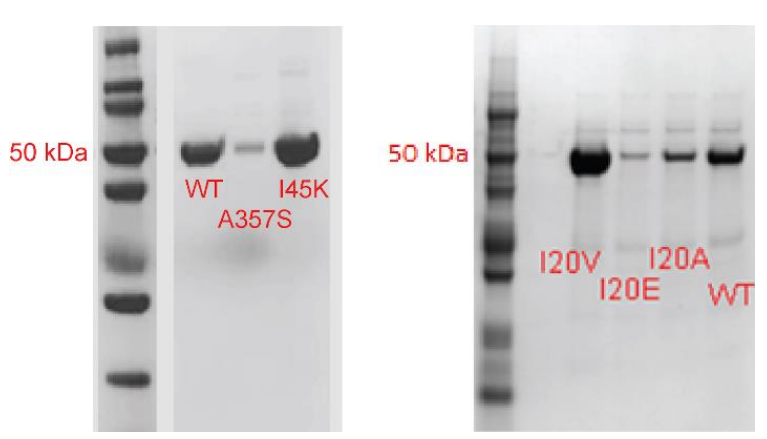

Figure 3. SDS-PAGE gel of two wild type and mutant enzymes. Sample bands formed at $50 \mathrm{kD}$, showing BglB purity. Mutants shown from left to right: I20V, 120E, 120A, A357S, $145 \mathrm{~K}$. 
bioRxiv preprint doi: https://doi.org/10.1101/2020.10.07.330233; this version posted October 7, 2020. The copyright holder for this preprint (which was not certified by peer review) is the author/funder, who has granted bioRxiv a license to display the preprint in perpetuity. It is made available under aCC-BY-NC-ND 4.0 International license.

\section{RESULTS}

\section{Interpreting Foldit Models}

The mutants $\mathrm{A} 357 \mathrm{~S}$ and $\mathrm{I} 20 \mathrm{E}$ were predicted to have a decreased $k_{\text {cat }} / \mathrm{K}_{\mathrm{M}}$ due to the positive change in ligand energy (Table 1), as well as observable changes in the hydrogen bonding adjacent to the active site, destabilizing the area (Figure 2). Mutants I20A, I20V, and I45K were predicted to have no change in $k_{\text {cat }} / \mathrm{K}_{\mathrm{M}}$ despite having a positive change in ligand energy (Table 1) because of the lack of observable changes to the intermolecular interactions between the substrate and the ligand (Figure 2). Mutant I45K was hypothesized to have an increase in overall thermal stability due to the negative change in the TSE value (Table 1). All other mutants were predicted to have a decreased thermal stability. From the data, we can see that mutants $\mathrm{I} 20 \mathrm{E}, \mathrm{I} 45 \mathrm{~K}$, and A357S were predicted accurately for $k_{\text {cat }} / \mathrm{K}_{\mathrm{M}}$, while mutants I20A, I20V, and A357S were predicted accurately for thermal stability.

\section{Expression Results}

All mutants expressed and purified as soluble protein above the detection limit $(0.1 \mathrm{mg} / \mathrm{mL})$ as previously defined in this system $^{6}$ based on A280 and SDS-PAGE analysis. There were varying levels of expression with mutants A357S, I20E, and I20A, having the lowest yields, only slightly higher than the detection limit (Table 1) and the lightest bands (Figure 3). Mutants I45K and I20V expressed at a higher level, with yields $>1.0 \mathrm{mg} / \mathrm{mL}$ concentration (Table 1) and the darkest bands (Figure 3).

\section{Kinetic Results}

The average wild type BglB $k_{\text {cat }} / \mathrm{K}_{\mathrm{M}}$ value was $62.9 \mathrm{mM}^{-1}$ $\min ^{-1}$ (Table 1), which falls within the range of typical $k_{\mathrm{cat}} / \mathrm{K}_{\mathrm{M}}$ values established by studies of this system ${ }^{8,9}$ and across enzyme systems more broadly. ${ }^{14}$ While a protein band was present in the I20E lane on the SDS-PAGE analysis, the enzyme had no quantifiable activity. Using the previously established limit for enzymatic activity detection of $10 \mathrm{M}^{-1} \mathrm{~min}^{-1}{ }^{8}$, only mutant (I20E) fell below this value. Mutant A357S had a $\mathrm{K}_{\mathrm{M}}$ double that of the wildtype and a $77 \%$ drop in $k_{\text {cat }}$ when compared to the wildtype, suggesting that interactions with the substrate were inhibited (Figure 4). For the mutants I20A and $\mathrm{I} 20 \mathrm{~V}$, we saw decreases in overall catalytic efficiency (approximately 91\% and 27\%, respectively). Mutant I45K saw similar results to the wildtype in catalytic efficiency $k_{\text {cat }} / K_{M}$.

\section{Thermal Stability Results}

The mean $\mathrm{T}_{\mathrm{M}}$ of wildtype $\mathrm{BglB}$ was determined to be $45.1^{\circ} \mathrm{C}$ (Table 1). No thermal data was collected for mutant I20E due low protein yield making reading unreliable. All other mutants had a decrease in thermal stability. The $T_{M}$ of the mutants A357S, I20A, I20V, and I45K were decrease by approximately $3{ }^{\circ} \mathrm{C}, 3{ }^{\circ} \mathrm{C}, 0.3^{\circ} \mathrm{C}$, and $2{ }^{\circ} \mathrm{C}$, respectively. All thermal data can be seen in Figure 5, as well as in Table 1.

\section{DISCUSSION}

In this study we found that three of the five predicted mutational effects for catalytic efficiency and three of the five predicted effects for thermal stability were supported by the data. Further, some patterns can be seen within the data that may be interesting to investigate.

Loss of catalytic efficiency was nearly ubiquitous across our small sample set; in reflecting back on the structural models, we
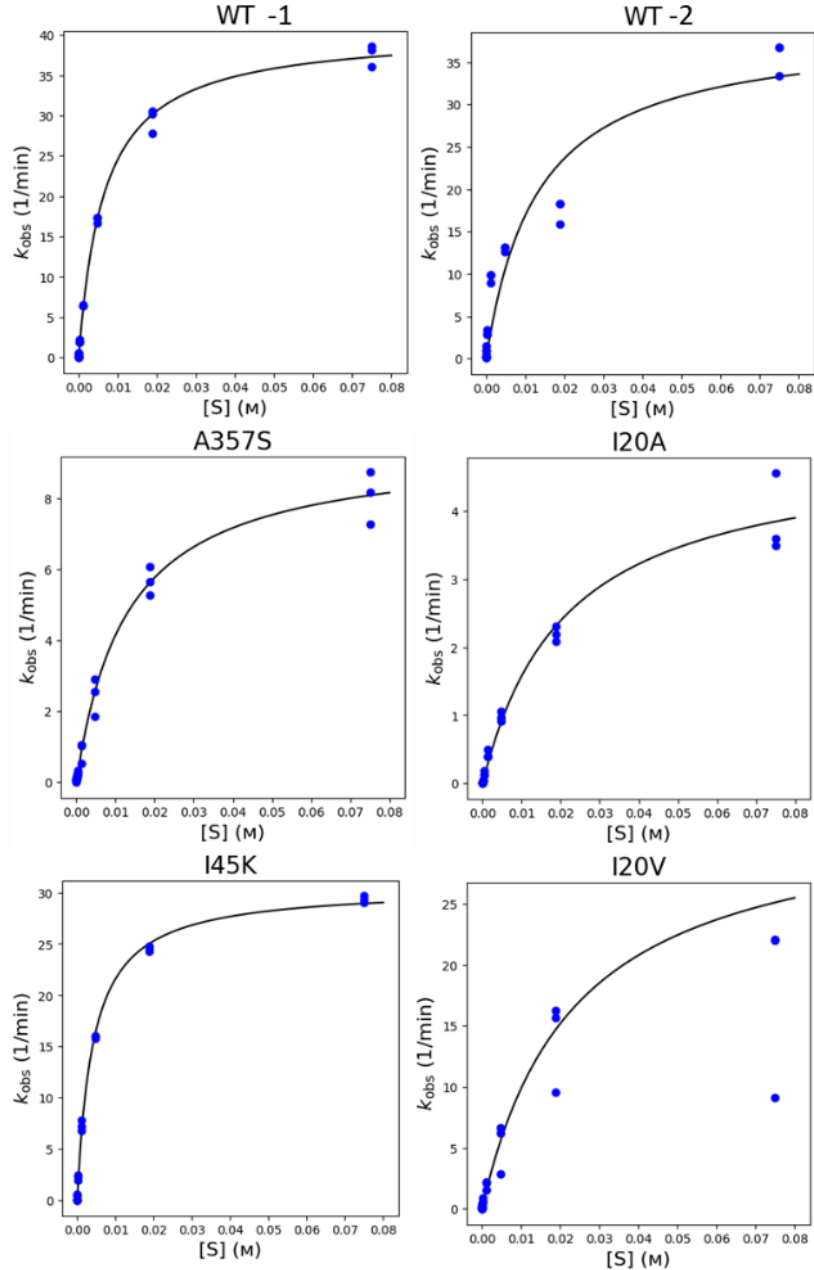

Figure 4. Observed turnover rate verses substrate concentration. Biological replicates of WT are presented as WT-1 and WT-2, all mutants and WT enzymes were assayed as technical triplicates with all data points shown in the plots. Concentrations of $\mathrm{pNG}$ are plotted on the horizontal axis with units of $\mathrm{M}$ and kobs on the vertical axis of $\mathrm{min}^{-1}$. The data above was fit through nonlinear regression to the Michaelis-Menten equation to determine $k_{\mathrm{cat}}$ and $\mathrm{K}_{\mathrm{M}}$, the best fit line for the triplicate data is illustrated in each panel.

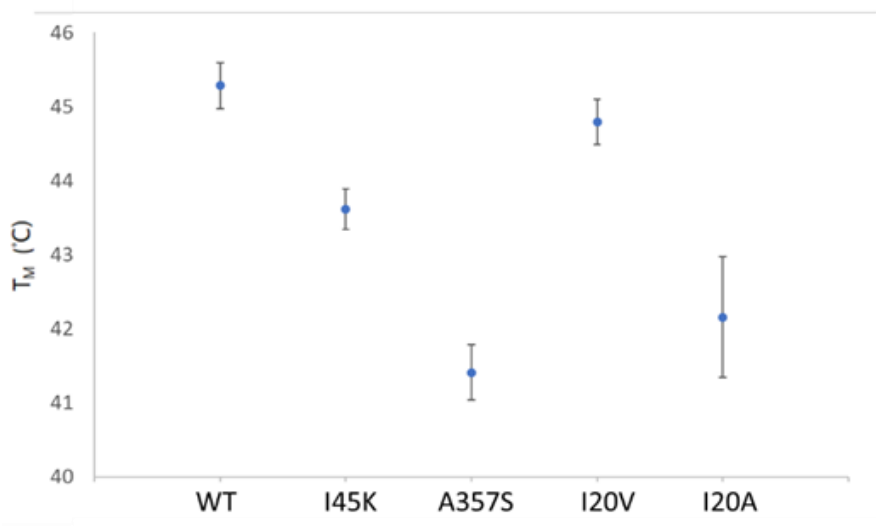

Figure 5. Thermal Stability of BglB Mutants. The $\mathrm{T}_{\mathrm{M}}$ values are in units of degrees Celsius. Bars indicate standard error from triplicate samples. WT-1 and WT-2 replicates are combined and reported as one WT. 
think we may be seeing an effect from changes in hydrogen bonding near the active site and from changes in the size of hydrophobic interactions. For example, the complete loss of activity of I20E might be due to a loss of a hydrogen bond near the active site between S400 and N404 in exchange of a hydrogen bond between the mutant and N404. And the striking decrease in activity of A357S may have been due to the hydrogen bond that was created between the serine and the backbone of the protein structure, causing an unfavorable structural change for binding affinity. For both I20A and I20V, we hypothesized that the reduction we saw in catalytic efficiency might be due to the decrease in size of the hydrophobic group, resulting in a loss of hydrophobic interaction which decreased protein stability and substrate affinity. Similar results were previously observed with the mutant V401A in a study by Chengrui Hou et al 2019. ${ }^{15}$

To further support the idea that hydrogen bonding has a considerable effect, the mutant $\mathrm{I} 45 \mathrm{~K}$ did not seem to affect catalytic efficiency $k_{\mathrm{cat}} / \mathrm{K}_{\mathrm{M}}$. This is may have been due to the lack of new hydrogen bonding that was formed, resulting in very similar interactions between the mutant and the wildtype.

We observed an overall trend between expression and activity and thermal stability. As expression (Yield, Table 1) increases, so does thermal stability and catalytic efficiency. Those that had the lowest levels of expression were the most disruptive mutations, causing changes to the hydrogen bonding that occurred within the protein structure (I20E and A357S) as opposed to changes occurring between the protein and the ligand. These are consistent with existing rules of protein folding. ${ }^{16}$

We can see this with more clarity when looking at the mutations at the I20 position. When comparing mutants I20A, $\mathrm{I} 20 \mathrm{~V}$, and the wildtype, we think we see a relationship in that the size of a non-polar amino acid, defined by the number of carbon atoms in the amino acid, leading to a decrease in both thermal stability and catalytic efficiency. These mutants do not change the hydrogen bonding in the protein, in contrast to mutant I20E, where a hydrogen bond is lost in favor of another. This change in hydrogen bonding coincided with low expression levels and catalytic efficiency falling below the detectable level.

The effects that hydrogen bonding on enzyme functionality have been previously examined. It was observed that the hydrogen bond energy of protein side chains had the strongest correlation with the $\mathrm{T}_{\mathrm{M}}$ of the enzyme when compared to other features. ${ }^{9}$ This was also observed in the Pearson correlations presented in Carlin et al. 2016, where there was a positive correlation between $1 / \mathrm{K}_{M}$ and the total number of hydrogen bonds in BglB. ${ }^{8}$ These findings align with the values for mutations at the $\mathrm{I} 20$ position in this study.

By focusing in on one site of the protein, we were able to observe how different interactions changed enzyme functionality. This study further stresses the importance of hydrogen bonding, not only between the substrate and the enzyme, but also within the structure of the enzyme. Finally, these findings show that focusing in on one position of a protein may help glean new information on enzyme functionality that may be useful in protein design. These mutants add to the Design to Data efforts to catalog the effects of a single point mutation on BglB.

\begin{tabular}{|c|c|c|c|c|c|c|c|}
\hline Mutants & $\Delta \mathrm{TSE}$ & $\Delta$ LigandE & Yield $(\mathrm{mg} / \mathrm{mL})$ & $k_{\text {cat }}\left(\mathrm{min}^{-1}\right)$ & $\mathrm{K}_{\mathrm{M}}(\mathrm{mM})$ & $k_{\mathrm{cat}} / \mathrm{K}_{\mathrm{M}}\left(\mathrm{min}^{-1} \mathrm{mM}^{-1}\right)$ & $\mathrm{T}_{\mathrm{M}}\left({ }^{\circ} \mathrm{C}\right)$ \\
\hline WT (Average) & 0.000 & 0.000 & 0.523 & $622.0 \pm 45.8$ & $9.8 \pm 2.2$ & $62.9 \pm 11.5$ & $45.1 \pm 0.1$ \\
\hline A357S & 0.117 & 0.237 & 0.148 & $92.8 \pm 3.2$ & $12.7 \pm 1.4$ & $7.3 \pm 0.8$ \\
\hline I45K & -3.148 & 0.009 & 1.136 & $299.9 \pm 2.4$ & $4.2 \pm 0.1$ & $72.0 \pm 2.4$ & $43.6 \pm 0.3$ \\
\hline I20A & 1.693 & 0.742 & 0.168 & $92.7 \pm 2.1$ & $17.1 \pm 1.1$ & $5.4 \pm 0.4$ \\
\hline I20E & 1.133 & 0.300 & 0.145 & N/A & N/A & $42.2 \pm 0.8$ \\
\hline I20V & 0.381 & 0.090 & 1.225 & $564.0 \pm 7.5$ & $12.7 \pm 0.53$ & N/A \\
\hline
\end{tabular}

Table 1. $\Delta$ Total System Energy Score, Expression, $\boldsymbol{k}_{\mathrm{cat}}, \mathbf{K}_{\mathrm{M}}, \boldsymbol{k}_{\mathrm{cat}} / \mathbf{K}_{\mathrm{M}}, \mathbf{T}_{\mathrm{M}}$ of five mutations and two wildtypes. Summary of the data collected for all mutants. The two wild type data sets have been combined as the average between the two. Technical triplicate data was collected for each mutant and all parameters, the standard deviation for the best fit data is provided. 
bioRxiv preprint doi: https://doi.org/10.1101/2020.10.07.330233; this version posted October 7, 2020. The copyright holder for this preprint (which was not certified by peer review) is the author/funder, who has granted bioRxiv a license to display the preprint in perpetuity. It is made available under aCC-BY-NC-ND 4.0 International license.

\section{ACKNOWLEDGEMENTS}

This work was supported by the University of California Davis, the National Institutes of Health (R01 GM 076324-11), the National Science Foundation (award nos. 1827246, 1805510, and 1627539), and the National Institute of Environmental Health Sciences of the National Institutes of Health (award no. P42ES004699). The content is solely the responsibility of the authors and does not necessarily represent the official views of the National Institutes of Health, National Institute of Environmental Health Sciences, National Science Foundation, or UC Davis.

\section{REFERENCES}

1. Badenhorst, Christoffel PS, and Uwe T. Bornscheuer. Getting momentum: from biocatalysis to advanced synthetic biology. Trends in biochemical sciences. 2018. 43, no. 3: 180-198. doi:10.1016/j.tibs.2018.01.003

2. Gordon SR, Stanley EJ, Wolf S, Toland A, Wu SJ, et al. (2012) Computational design of an $\alpha$-Gliadin Peptidase. Journal of the American Chemical Society 134: 20513 20520. pmid:23153249

3. Robinson PK. Enzymes: principles and biotechnological applications. Essays Biochem. 2015. doi:10.1042/BSE0590001

4. H.M. Berman, J. Westbrook, Z. Feng, G. Gilliland, T.N. Bhat, H. Weissig, I.N. Shindyalov, P.E. Bourne. (2000) The Protein Data Bank Nucleic Acids Research, 28: 235-242.

5. Huang $\mathrm{P}$, Contreras SC, Bloomfield E, Schmitz K, Arredondo A, Siegel JB. Design to Data for mutants of $\beta$ glucosidase B from Paenibacillus polymyxa: M319C, T431I, and K337D. bioRxiv. 2019 Jan 1:839027.

6. Alford, R. F.; Leaver-Fay, A.; Jeliazkov, J. R.; O’Meara, M. J.; DiMaio, F. P.; Park, H.; Shapovalov, M. V; Renfrew, P. D.; Mulligan, V. K.; Kappel, K.; et al. The Rosetta All-Atom Energy Function for Macromolecular Modeling and Design. J. Chem. Theory Comput. 2017, 13 (6), 3031-3048. https://doi.org/10.1021/acs.jctc.7b00125.

7. Mak WS, Siegel JB. Computational enzyme design: Transitioning from catalytic proteins to enzymes. Current opinion in structural biology. 2014 Aug 1;27:87-94.
8. Carlin DA, Caster RW, Wang X, et al. Kinetic characterization of 100 glycoside hydrolase mutants enables the discovery of structural features correlated with kinetic constants. PLoS One. 2016. doi: 10.1371/journal.pone.0147596

9. Carlin DA, Hapig-Ward S, Chan BW, et al. Thermal stability \& kinetic constants for 129 variants of a family 1 glycoside hydrolase reveal that enzyme activity \& stability can be separately designed. PLoS One. 2017. doi:10.1371/journal.pone.0176255

10. Kleffner R, Flatten J, Leaver-Fay A, et al. Foldit Standalone: a video game-derived protein structure manipulation interface using Rosetta. Bioinformatics. 2017. doi:10.1093/bioinformatics/btx283

11. DeLano WL. The PyMOL Molecular Graphics System, Version 1.1. Schr\{ö\}dinger LLC. 2002. doi: $10.1038 / \mathrm{hr} .2014 .17$

12. Kunkel TA. Rapid and efficient site-specific mutagenesis without phenotypic selection. Proc Natl Acad Sci U S A. 1985. doi:10.1073/pnas.82.2.488

13. Roskoski R. Michaelis-menten kinetics. In: XPharm: The Comprehensive Pharmacology Reference; 2007. doi:10.1016/B978-008055232-3.60041-8.

14. Bar-Even A, Noor E, Savir Y, Liebermeister W, Davidi D, Tawfik DS, Milo R. The moderately efficient enzyme: evolutionary and physicochemical trends shaping enzyme parameters. Biochemistry. 2011 May 31;50(21):4402-10. dx.doi.org/10.1021/bi2002289

15. Hou, C., Smith, P., Huang, J., Fell, J.S., Huang, P., Vater, A. and Siegel, J.B. Design to Data for mutants of $\beta$-glucosidase B from Paenibacillus polymyxa: Q22T, W123R, F155G, Y169M, W438D, V401A. bioRxiv. 2019. doi: https://doi.org/10.1101/2019.12.23.887380

16. Fersht A. Structure and Mechanism in Protein Science: A Guide to Enzyme Catalysis and Protein Folding. Macmillan; 1999. 